Xavier, MVB., Fonseca, APM, Almeida, ES, \& Oliveira, PVA. (2020). Management of Oncideres ocularis Thomson in Mimosa caesalpiniifolia Benth. Research, Society and Development, 9(7): 1-15, e787974601.

\title{
Manejo do Oncideres ocularis Thomson em Mimosa caesalpiniifolia Benth.
}

Management of Oncideres ocularis Thomson in Mimosa caesalpiniifolia Benth.

Manejo do Oncideres ocularis Thomson en Mimosa caesalpiniifolia Benth.

Recebido: 16/05/2020 | Revisado: 24/05/2020 | Aceito: 30/05/2020 | Publicado: 13/06/2020

Márcio Venícius Barbosa Xavier

ORCID: https://orcid.org/0000-0002-6903-1601

Instituto de Ciências Agrárias da Universidade Federal de Minas Gerais, Brasil

E-mail: mvbx293@gmail.com

Ana Paula Mota Fonseca

ORCID: https://orcid.org/0000-0002-6847-5411

Instituto de Ciências Agrárias da Universidade Federal de Minas Gerais, Brasil

E-mail: anapaulamota577@gmail.com

Elaine Soares de Almeida

ORCID: https://orcid.org/0000-0001-5417-3087

Instituto de Ciências Agrárias da Universidade Federal de Minas Gerais, Brasil

E-mail: elainesoaresalmeida2015@gmail.com

Paulo Victor Alves de Oliveira

ORCID: https://orcid.org/0000-0002-1637-6534

Instituto de Ciências Agrárias da Universidade Federal de Minas Gerais, Brasil

E-mail: paulovictor3491@gmail.com

\section{Resumo}

Mimosa caesalpiniifolia é uma árvore leguminosa nativa e endêmica do Brasil com distribuição geográfica na Caatinga, Cerrado, Amazônia e Mata Atlântica. Seu nome popular mais difundindo é Sabiá. A espécie é comumente empregada em programas de recuperação de áreas degradadas, construção de cercas vivas, fabricação de postes e mourões, constituição de florestas energéticas, produção de forragem, além de ser melífera, ornamental e utilizada na medicina tradicional, por isso, dispõe de múltiplos usos. No entanto, é vulnerável aos ataques do besouro Oncideres ocularis, pertencente a ordem coleóptera. Ele apresenta rápida reprodução e é o responsável por impedir o desenvolvimento saudável de mudas e árvores, 
inviabilizando o seu uso para diversos fins. Assim, torna-se necessária a adoção de um manejo integrado de pragas, através do seu monitoramento constante e utilização de técnicas de controle mecânico e físico. Dessa forma, objetivou-se realizar uma revisão bibliográfica sobre o manejo do Oncideres ocularis em Mimosa caesalpiniifolia.

Palavras-chave: Manejo integrado; Besouro serrador; Controle de pragas; Sabiá.

\begin{abstract}
Mimosa caesalpiniifolia is a leguminous tree native and endemic to Brazil with geographic distribution in the Caatinga, Cerrado, Amazon and Atlantic Forest. Its most popular name is Sabiá. The species is commonly used in programs for the recovery of degraded areas, the construction of hedges, the manufacture of posts and fence posts, the formation of energy forests, the production of forage, in addition to being meliferous, ornamental and used in traditional medicine, therefore, has multiple uses. However, the species is vulnerable to attacks by the beetle Oncideres ocularis, belonging to the coleoptera order. It is fast to reproduce and is responsible for preventing the healthy development of seedlings and trees, preventing its use for various purposes. Thus, it becomes necessary to adopt an integrated pest management, through its constant monitoring and the use of mechanical and physical control techniques. Thus, the objective was to carry out a bibliographic review on the management of Oncideres ocularis in Mimosa caesalpiniifolia.
\end{abstract}

Keywords: Integrated management; Sawdust beetle; Pest control; Sabiá.

\title{
Resumen
}

Mimosa caesalpiniifolia es un árbol leguminoso nativo y endémico de Brasil con distribución geográfica em la Caatinga, Cerrado, Amazonas y Mata Atlántica. Su nombre más popular es Sabiá. La especie se usa comúnmente en programas para la recuperación de áreas degradadas, la construcción de setos, la fabricación de postes y postes, la formación de bosques energéticos, la producción de forraje, además de ser melífera, ornamental y utilizada en medicina tradicional, por lo tanto, tiene múltiples usos. Sin embargo, la especie es vulnerable a los ataques del escarabajo Oncideres ocularis, perteneciente al orden de los coleópteros. Tiene una reproducción rápida y es responsable de prevenir el desarrollo saludable de plántulas y árboles, evitando su uso para diversos fines. Así, se hace necesario adoptar un manejo integrado de plagas, a través de su monitoreo constante y el uso de técnicas de control mecánico y físico. Así, el objetivo fue realizar una revisión bibliográfica sobre el manejo de Oncideres ocularis en Mimosa caesalpiniifolia. 
Palabras clave: Gestión integrada; Escarabajo de aserrín; Control de plagas; Sabiá.

\section{Introdução}

Mimosa caesalpiniifolia Benth. é uma árvore leguminosa conhecida popularmente, a depender da região, como cebiá, sabiá, sansão-do-campo e unha-de-gato, sendo sabiá o nome popular mais difundido. Nativa e endêmica do Brasil, já foi catalogada nos ecossistemas Caatinga, Cerrado, Amazônia e Mata Atlântica. Naturalmente, a espécie se distribui nos estados de Alagoas, Bahia, Ceará, Maranhão, Paraíba, Pernambuco, Piauí, Rio Grande do Norte, Sergipe e Minas Gerais, mas, devido a ação humana, é registrada atualmente em 21 estados (região Norte: Amazonas, Pará, Rondônia; Nordeste: Bahia, Ceará, Maranhão, Paraíba, Pernambuco, Piauí, Rio Grande do Norte; Centro-Oeste: Distrito Federal, Goiás, Mato Grosso do Sul; Sudeste: Espírito Santo, Minas Gerais, Rio de Janeiro, São Paulo e Sul :Paraná, Santa Catarina), abrangendo as cinco regiões do país (Flora do Brasil, 2020).

Trata-se de uma espécie com múltiplos usos e representativo valor comercial. No entanto, é vulnerável ao ataque do besouro Oncideres ocularis, que impede o desenvolvimento saudável de mudas e árvores, interferindo diretamente na sobrevivência, pois danificam o corpo vegetal e se reproduzem rapidamente, intensificando os danos (Alves, 2011). O Fato torna inviável o uso da espécie para extração de madeira, produção de mudas, plantios de pequena a larga escala, programas de recuperação de áreas degradadas, arborização urbana e outras atividades.

Dessa forma, objetivou-se realizar uma revisão bibliográfica sobre o manejo do Oncideres ocularis em Mimosa caesalpiniifolia, principal inseto-praga da espécie.

\subsection{Mimosa caesalpiniifolia Benth}

A espécie é semicaducifólia, apresenta ritidoma marrom-escamoso, folhas recompostas, ramos com espinhos, flores branco-creme, inflorescência tipo espiga, e, apresenta-se naturalmente com porte médio (4-10m de altura) (Figura 1). 
Figura 1. Mimosa caesalpiniifolia: (A) hábito de vida, (B) ritidoma escamoso, (C) ramos jovens, (D) (E) folhas e (F) inflorescência.
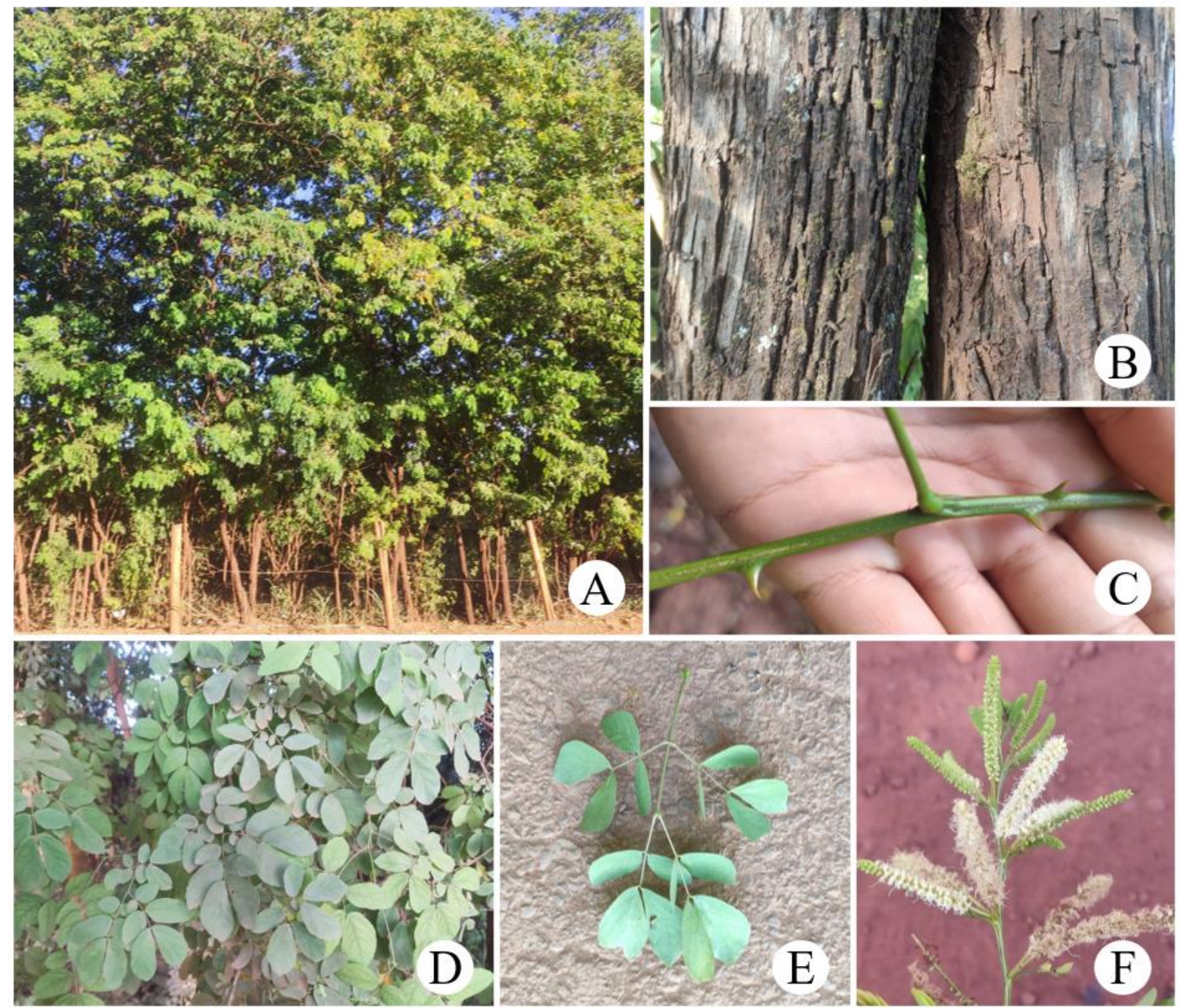

Fonte: Dos autores, 2020.

Na Figura 1, observa-se por meio das fotografias de A à $\mathrm{F}$ as principais características morfológicas de M. caesalpiniifolia, demonstrando de forma visual órgãos vegetativos (caule, ramos e folhas) e reprodutivos (inflorescência (conjunto das flores)). É mostrado desde o comportamento da espécie quando agrupada e seu hábito de vida arbóreo com crescimento entouceirado (vários caules se originando do mesmo ponto) em A, a características do caule evidenciando o ritidoma (popularmente conhecido como casca) com padrão escamoso em B, ramos jovens com espinhos em $\mathrm{C}$, disposição das folhas nos ramos, tipo de folha e inflorescência (conjunto das flores) tipo espiga em D, E e F, respectivamente.

Mimosa caesalpiniifolia ocorre espontaneamente em terrenos profundos, principalmente em solos arenosos. Em função de sua baixa exigência em fertilidade e 
umidade, apresenta bom desenvolvimento em solos mais pobres, contudo, para atividades com fins comerciais, é recomendado que a planta seja suprida com nutrientes por meio de adubação orgânica ou química para que obtenha melhores resultados de produção e qualidade da madeira (Ribaski et al., 2003). Ressalta-se que características que favorecem o uso da espécie em atividades comerciais, como forma de crescimento e baixa exigência nutricional também contribuíram para o atual status de invasora em algumas áreas no Brasil (Base de dados nacional de espécies exóticas invasoras, 2020).

Devido seu rápido crescimento e elevada capacidade de rebrota, apresenta potencial para compor programas de recuperação de ambientes alterados (Maia, 2004). Além disto, é uma importante espécie mantenedora da produção de mel no Nordeste brasileiro (De Mello Pereira, 2004).

A madeira é utilizada na fabricação de estacas, postes, portas, mourões, dormentes e varas, além de ser alternativa para constituição de florestas energéticas para a produção de carvão vegetal e lenha, devido boas características físico-químicas.

Outros usos da madeira compreendem tutores para apoio e sustentação das plantações de uvas (Serra, 1997), quebra-vento ou cerca-viva em fazendas, loteamentos, indústrias e áreas de mineração (Barbosa, Silva \& Barroso, 2008).

As folhas, de alto valor nutritivo, e frutos maduros ou secos são forragens para bovinos, caprinos e ovinos. A infusão da casca é usada como expectorante ou tônico no tratamento de doenças respiratórias como a bronquite e, de uso externo, a decocção das cascas é usada para estancar sangramentos e lavagem de ferimentos (Agra et al., 2008; Ribaski et al., 2003).

A inflorescência é usada pela população do semiárido brasileiro no preparo de chá para o tratamento da hipertensão (Santos et al., 2015). Além do mais, a árvore apresenta características ornamentais, principalmente pelo crescimento entouceirada (Carvalho, 2007).

No entanto, Mimosa caesalpiniifolia pode ser atacada em qualquer fase da vida por Oncideres ocularis (Coleóptero), principal inseto-praga da espécie. Conhecido popularmente como viga-de-galho, $O$. ocularis realiza anelamento dos galhos e, logo após, a fêmea usando suas mandíbulas, abre fissuras, onde guarda seus ovos (Figura 2) (Monné, 2002; Vulcano \& Pereira, 1978). Em geral, Oncideres spp. são alguns dos insetos mais importantes em relação à geração de injúrias e danos mecânicos na família botânica Fabaceae (Monné, 2002; Vulcano \& Pereira, 1978). 
Figura 2. Ataque do Oncideres ocularis em Mimosa caesalpiniifolia.

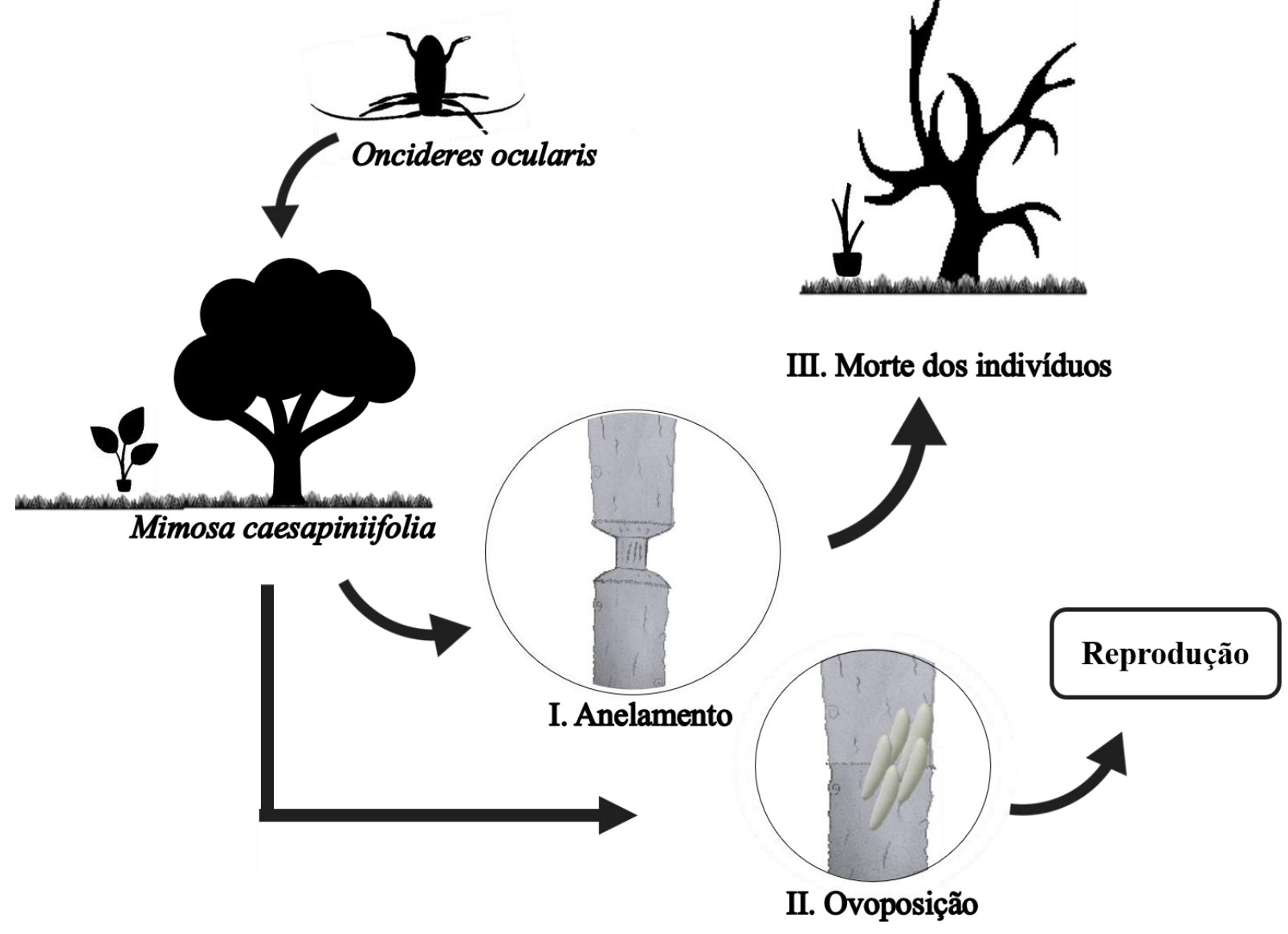

Fonte: Dos autores, 2020.

Na Figura 2, é esquematizado o processo do ataque do $O$. ocularis em $M$. caesalpiniifolia; o item I exemplifica o anelamento dos ramos no indivíduo jovem (muda) ou adulto (árvore) causado pelo inseto seguido de sua consequência para a planta em III, indicando a morte do indivíduo. O item II demonstra a ovoposição do inseto nas fissuras feitas pelo mesmo, ato que caracteriza a parte do seu ciclo de reprodução que é dependente da planta.

Os ovos do Oncideres ocularis são de coloração branca, as larvas recém-eclodidas possuem cor amarelo-pálido e seus corpos são providos de pelos curtos (Alves, 2011). Os machos são diferenciados das fêmeas devido ao comprimento do último segmento antenal, sendo que na fase adulta a diferenciação entre macho e fêmea é a forma do último segmento abdominal, tendo a forma de " $\mathrm{v}$ " invertido nos machos e arredondado nas fêmeas. Estes insetos passam a maior parte da vida na fase larval, vivendo cerca de um a três anos como larva, e apenas alguns dias como adulto após o acasalamento (Alves, 2011). 


\section{Metodologia}

Este estudo consiste em uma revisão bibliográfica de caráter qualitativo, com base nas diretrizes propostas por Pereira, Shitsuka, Parreira \& Shitsuka (2018), a respeito do manejo do Oncideres ocularis em Mimosa caesalpiniifolia.

A delimitação do tema proposto baseou-se na escassez de informações disponíveis na literatura, na contribuição que esta pesquisa fornecerá para outros trabalhos da comunidade científica e no conhecimento que a mesma proporcionará. Após delimitação do tema, foi estipulado um período de tempo para a coleta de dados, a qual foi realizada nos meses de fevereiro e março de 2020.

As fontes de dados utilizadas consistiram em portais eletrônicos, por meio de busca nas plataformas Periódicos da CAPES (Coordenação de Aperfeiçoamento de Pessoal de Nível Superior), Google scholar, Scielo (Scientific Electronic Library Online) e Elsevier. As plataformas foram selecionadas de acordo a disponibilidade de consulta e relevância, permitindo o acesso a diversos periódicos nacionais e internacionais indexados.

Foi definido como critério de inclusão os artigos publicados em periódicos, circulares técnicas e notas científicas, nos idiomas português, inglês e espanhol, sem definição de um parâmetro cronológico, já que há poucos exemplares disponíveis. Outro critério considerado foram os descritores: Oncideres ocularis, Mimosa caesalpiniifolia e manejo, visto que as respectivas palavras englobam as principais expressões objeto de investigação deste estudo. Assim, delimitou-se os documentos de interesse para a realização da pesquisa.

Após a seleção dos artigos conforme os critérios supracitados, foi realizada a leitura exploratória; leitura seletiva e escolha do material com base nos objetivos e tema deste estudo. Foi feita a análise dos textos, finalizando com a realização de leitura interpretativa e redação do trabalho.

\section{Resultados e Discussão}

\subsection{Monitoramento do Oncideres ocularis Thomson}

O manejo de pragas florestais está altamente vinculado ao monitoramento, uma vez que existe grande necessidade de identificar os sítios com maiores densidades populacionais, pois estes já podem ter excedido os limiares econômicos (Wylie \& Speight, 2012). Os autores ainda alertam que devido as dimensões dos plantios florestais, muitas vezes o monitoramento 
correto e eficaz é dificultado.

A maioria das tecnologias utilizadas no monitoramento de pragas florestais nos países desenvolvidos, como por exemplo, armadilhas com semioquímicos, ainda possuem custo elevado. Associado a isto, pesquisas dessa categorização são escassas e exigem considerável investimento, assim, os fatos contribuem para o baixo percentual de uso dessas armadilhas, principalmente em países tropicais (Nadel et al., 2012).

Países com clima tropical e detentores de grandes extensões florestais como o Brasil, têm a observação dos trabalhadores a maneira mais simples e eficiente de se notar qualquer desordem nos empreendimentos florestais. Assim, os profissionais tomarão as medidas apropriadas; ressaltando que estes "olhos na floresta" são um componente importante no monitoramento (Wylie \& Speight, 2012).

As técnicas de monitoramento variam de acordo o tipo de floresta. Em plantios florestais, normalmente se utiliza uma combinação de técnicas aéreas e terrestres. As técnicas terrestres envolvem dirigir e caminhar pela área de plantio, geralmente uma equipe de dois observadores dirigem nas estradas em baixa velocidade procurando por sintomas ou sinais de pragas; as rotas são planejadas para fornecer uma amostragem sistemática da área (Figura 3) (Bulman et al., 1999). As técnicas aéreas podem ser conduzidas na forma de esboço cartográfico, o que consiste em delinear a área do dano em mapas baseados na observação de especialistas em saúde florestal sobrevoando em uma pequena aeronave e/ou usando fotografias aéreas, compreendendo a utilização de imagens coloridas e infravermelhocoloridas para estimar o nível do dano e a mortalidade gerada pela praga (Figura 3) (Pywell \& Myhre, 1992; Johnson \& Ross, 2008).

Figura 3. Monitoramento do Oncideres ocularis em plantios de Mimosa caesalpiniifolia.
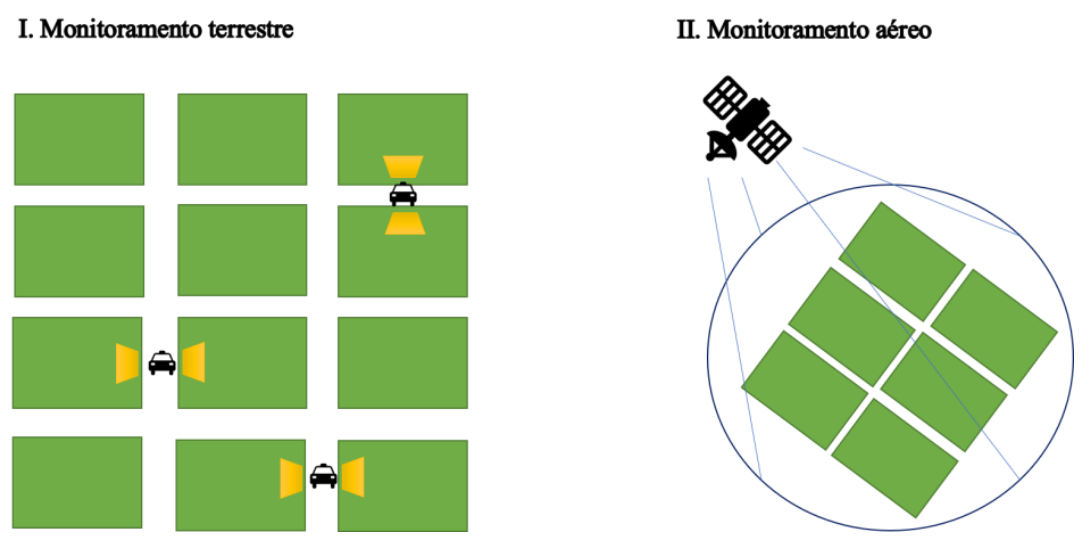

Fonte: Dos autores, 2020. 
Na Figura 3, é esquematizado as técnicas de monitoramento para e controle do $O$. ocularis, junto com as principais diferenças entre os monitoramentos, isto é, terrestre e aéreo. Percebe-se que no monitoramento terrestre (item I) há rondas motorizadas em rotas previamente planejadas, e no monitoramento aéreo (item II) é feito a delimitação das áreas por mapas e as áreas de interesse são fotografadas com o auxílio de VANTs (Veículos Aéreos Não Tripulados).

\subsection{Estratégias e táticas de manejo de pragas}

Insetos se tornam pragas em decorrência de fatores como a expansão da área de plantio de uma espécie, uso de material genético restritivo para atingir alta produtividade, bem como, a adoção de manejo silvicultural errôneo e fragmentação dos ecossistemas florestais nativos nas proximidades dos empreendimentos. $\mathrm{O}$ surto de pragas em povoamentos florestais segundo Iede (2012) se deve principalmente à ausência de inimigos naturais e a atributos biológicos, o que eleva a necessidade em elaborar programas de controle de pragas que sejam racionais e econômicos.

\subsubsection{Manejo Integrado de Pragas (MIP)}

A adoção de medidas inadequadas de controle agrava o problema, devido ao desconhecimento das relações ecológicas que ocorrem entre o hospedeiro, a praga e seus inimigos naturais, e das condições de clima e solo (Ibid, 2012). O manejo integrado de pragas (MIP) surge como uma etapa importante e decisiva para o empreendimento florestal, uma vez que consiste no uso de todas as técnicas de controle disponíveis de maneira integrada, a fim de reduzir danos econômicos causados por pragas com menos efeitos nocivos ao ambiente e ao ser humano (Zanetti, 2005; Picanço, Gonring \& Oliveira, 2010).

O conceito de MIP foi e é amplamente difundido e bastante defendido para os cultivos florestais (Sousa et al., 2005). Desta forma, como no MIP todos os métodos de controle têm seu espaço e importância, quando se tratam de plantios florestais, o uso de agrotóxicos apresenta sérias restrições, devendo ser usado apenas como último recurso, no intuito de manter a estabilidade do ecossistema, ou quando trata-se de plantios com maior valor agregado. Por outro lado, o controle biológico, assim como os métodos físicos, silviculturais e mecânicos são os que apresentam grande potencial de uso e de integração (Iede, 2012).

Sabe-se que cada método de controle possui sua relevância. No entanto, 
particularmente, nenhum deles tem se mostrado em uma alternativa razoável aos inúmeros problemas apresentados pelas pragas nos plantios florestais, e a utilização de medidas inadequadas de combate podem criar impasses maiores do que aqueles que deveriam ser resolvidos. Sendo assim, após um longo período de uso intensivo de produtos químicos, o MIP é um caminho promissor, que, por meio de uma relação mútua tem permitido avanços no setor florestal para pequenos e grandes produtores com adoção de práticas mais eficazes, com maior segurança ambiental, social e econômica.

\subsubsection{Controle silvicultural}

Inspecionar periodicamente o plantio a fim de detectar antecipadamente os surtos, conhecer a distribuição geográfica da praga e, posterior avaliação da densidade populacional e definição do melhor momento de intervenção com vistas ao controle da incidência e aumento da densidade populacional do Oncideres ocularis (Zanetti et al., 2005).

Remoção de todos os restos mortais (Fig.4): esse recurso não extermina a atividade do Oncideres ocularis, visto que constantemente há probabilidade de reinfestação de adultos em locais com grande número de hospedeiros nativos ou de outros plantios contíguos. Quando executado corretamente, minimiza o aumento populacional da praga a índices toleráveis pela cultura e impede o desenvolvimento da postura, limitando o número de larvas que formarão a próxima geração. Essa dinâmica deve ser executada em plantios jovens, pois apresenta resultados mais eficientes e terá de ser aplicada como atividade complementar de controle.

Figura 4. Remoção e descarte dos restos mortais de Mimosa caesalpiniifolia com larvas do Oncideres ocularis.

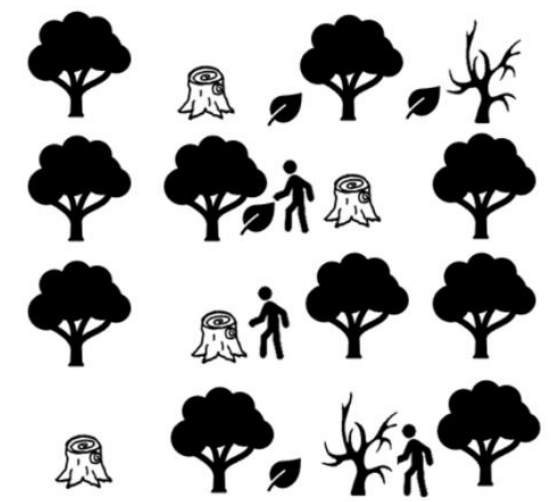

I. Remoção dos restos mortais

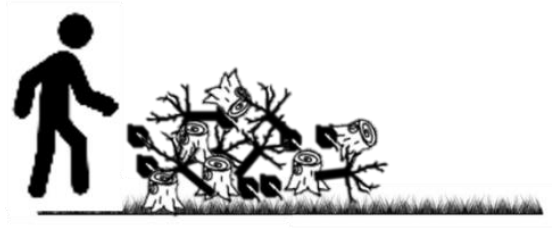

II. Descarte em local apropriado

Fonte: Dos autores, 2020. 
A Figura 4 representa as medidas silviculturais que podem ser tomadas afim de se ter controle sobre a incidência do $O$. ocularis. Observa-se a remoção de todos os resíduos da área seja folhas, galhos, árvores mortas e outros (item I), seguido pelo descarte em local adequado (Item II).

Os troncos ou galhos infestados deverão ser devidamente descartados, dado que as larvas completam o seu ciclo de vida em material empilhado (Figura 4) (Zanetti et al., 2005).

\subsubsection{Controle físico e mecânico}

Uso de frascos com orifícios grandes, contendo mel ou melaço na concentração de $10 \%$, para confinar os insetos (Figura 5), associado à constante vistoria no plantio. A substância deve ser reposta toda semana. Torna-se necessário aumentar a quantidade de frascos nos locais de maior confinamento. Essa técnica deve ser executada em toda a área de ocorrência do inseto a fim de prevenir reinfestação (Zanetti et al., 2005).

Figura 5. Armadilhas com mel e melaço para capturar Oncideres ocularis.

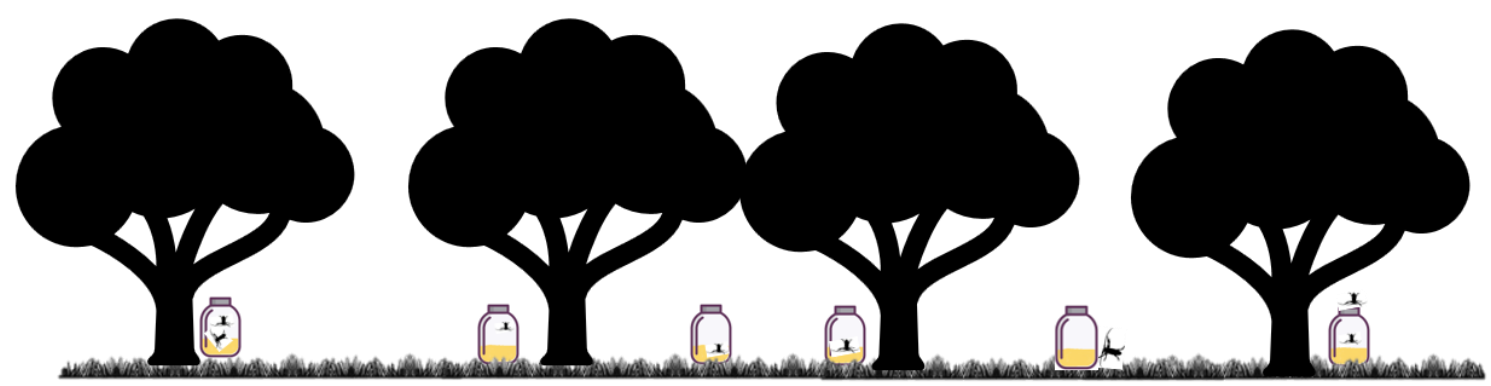

Fonte: Dos autores, 2020.

A Figura 5 esquematiza o controle mecânico que consiste em colocar na área de plantio armadilhas feitas com potes abertos contendo melaço ou mel. A substância atrai os insetos para dentro dos potes, que, em contanto com a mesma, não conseguem sair e morrem, diminuindo as chances de aumento populacional e posterior reinfestação.

Eliminar todos os galhos com larvas, tanto os que estiveram no solo quanto os que inicialmente ficaram suspensos nas árvores, utilizando fogo (Figura 6). A coleta dos galhos deverá ser realizada alguns meses após o encerramento total das atividades dos Oncideres ocularis. O recolhimento deverá ser realizado anualmente (Lima, 1940). 
Figura 6. Coleta e incineração dos galhos com larvas do Oncideres ocularis.

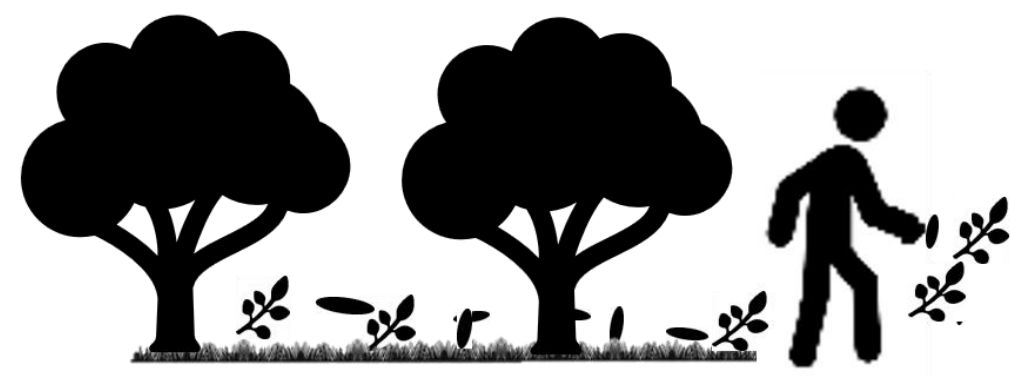

I. Coleta de galhos infectados

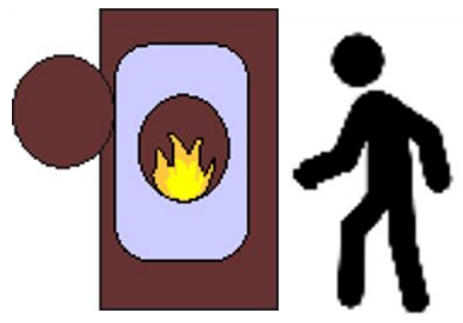

II. Incineração

Fonte: Dos autores, 2020.

Na Figura 6 é importante observar que é feita a remoção dos galhos infectados com ovos e larvas (item I) de O. ocularis, seguido pela incineração destes galhos (item II), garantindo maior eficácia no controle.

\subsubsection{Controle químico e biológico}

Não existe, até o momento, produto químico comercial registrado (Mapa, 2019) e não há registros na literatura sobre agentes de controle vivo para Oncideres ocularis.

A falta de produto químico comercial registrado para o controle do O. ocularis, devese, provavelmente, à escassez de estudos e conhecimento aprofundado sobre a biologia do inseto. A ausência de registros na literatura a respeito da utilização de agentes vivos, pode ser enfatizada pelos poucos estudos em relação a biologia da praga, dos seus inimigos naturais e da relação entre a praga e o inimigo natural.

\section{Considerações Finais}

Oncideres ocularis é um inseto-praga que pode causar prejuízos significativos à cultura de Mimosa caesalpiniifolia, tanto nos indivíduos jovens quanto adultos. O monitoramento desta praga deve ser constante e, entre as técnicas de controle, os mecânicos e físicos são os mais eficientes e de baixo custo. Quando utilizados de forma integrada, os resultados são potencializados. Atualmente, não existe controle químico e biológico para a praga nesta cultura.

Os artigos que abordam diretamente o manejo do Oncideres ocularis em Mimosa caesalpiniifolia, ainda são poucos. No entanto, as informações obtidas foram satisfatórias e contribuem para informação sobre o processo. Porém, alertam a necessidade de realização de 
pesquisas sobre este inseto-praga no que se refere a implantação de técnicas de combate e prevenção de danos gerados pela espécie. Desta forma, o objetivo da revisão bibliográfica foi atingido, visto que os trabalhos selecionados representam uma pequena amostra, mas significativa a respeito da pesquisa científica que vem sendo realizada sobre o assunto. Além disto, a análise destas informações fornece subsídios e suporte para a realização de pesquisas futuras.

\section{Referências}

Agra, M. D. F, Silva, K. N, Basílio, I. J. L. D, Freitas, P. F. D \& Barbosa-Filho, J. M. (2008). Survey of medicinal plants used in the region Northeast of Brazil. Revista brasileira de farmacognosia, 18(3), 472-508.

Alves, P. G. L. (2011). Bioecologia de Oncideres ocularis Thomson (col.: cerambycidae) (Doctoraldissertation, Universidade Federal de Viçosa).

Barbosa, T. R. L., Soares, M., \& Barroso, D. G. (2008). Plantio de sabiazeiro (Mimosa caesalpinifolia) em pequenas e médias propriedades. Niterói: Programa Rio Rural.

Base de dados nacional de espécies exóticas invasoras, I3N Brasil. Instituto Hórus de Desenvolvimento e Conservação Ambiental. Florianópolis - SC. Disponível em: http://bd.institutohorus.org.br/www.

Bulman, L. S., Kimberley, M. O., \& Gadgil, P. D. (1999). Estimation of the efficiency of pest detection surveys. New Zealand Journal of Forestry Science, 29(1), 102-115.

Carvalho, P. E. R. (2007). Sabiá - Mimosa caesalpiniifolia. Embrapa Florestas-Circular Técnica (INFOTECA-E).

De Mello Pereira, F., Freitas, B. M., Alves, J. E., Camargo, R. C. R., Lopes, M. T. R., Neto, J. M. V., Rocha, R. S. (2004). Flora apícola no Nordeste. Embrapa Meio-Norte-Documentos (INFOTECA-E). 
Iede, E. T. (2012). Manejo integrado de pragas florestais. In Embrapa Florestas-Artigo em anais de congresso (ALICE). In: CONGRESSO FLORESTAL PARANAENSE, 4., 2012, Curitiba. Anais. [Curitiba]: Malinovski Florestal, 2012. CD-ROM.

Johnson, E. W., \& Ross, J. (2008). Quantifyingerror in aerial survey data. Australian Forestry, 71(3), 216-222.

Lima, C. (1940). Insetos do Brasil (No. 595.7 LIM). Escola Nacional de Agricultura.

Maia, G. N., Maia, G. N., Maia, G. N., Maia, G., Maia, G. L., Maia, N., \& Maia Campos, P. M. B. G. (2004). Caatinga: árvores arbustos e suas utilidades.

Mapa (Ministério da Agricultura, Pecuária e Abastecimento). (2019). Agrofit. Disponível em: https://bit.ly/2na8kPO.

Mimosa in Flora do Brasil 2020 em construção. Jardim Botânico do Rio de Janeiro. Disponível em: http://reflora.jbrj.gov.br/reflora/floradobrasil/FB18776.

Monné, M. A. (2002). Catalogue on the Neotropical Cerambycidae (Coleoptera) with known host plant. PART IV: Subfamily Lamiinae, tribes Batocerini to Xenofreini. Publ. Avulsas Mus. Nac, 94, 92.

Nadel, R. L., Wingfield, M. J., Scholes, M. C., Lawson, S. A., \& Slippers, B. (2012). The potential for monitoring and control of insect pests in Southern Hemisphere forestry plantations using semiochemicals. Annals of Forest Science, 69(7), 757-767.

Picanço, M. C., Gonring, A., Oliveira, I. D. (2010). Manejo integrado de pragas. Viçosa: Universidade Federal de Viçosa.

Pywell, H. R., \& Myhre, R. J. (1992, January). Monitoring forest health with airborne videography. In Integrating forest information over space and time: IUFRO Conference, 1317 January, 1992, Canberra, Australia (p. 349). ANUTECH. 
Ribaski, J., Lima, P. C. F., de Oliveira, V. R., \& Drumond, M. A. (2003). Sabiá (Mimosa caesalpiniaefolia) árvore de múltiplo uso no Brasil. Embrapa Florestas-Comunicado Técnico (INFOTECA-E).

Serra, M. T. (1997). RedLatinoamericana de Cooperación Técnica en Sistemas Agroforestales: Especies arbóreas y arbustivas para las zonas áridas y semiáridas de América Latina.

Santos, M. E. P., Moura, L. H. P., Mendes, M. B., Arcanjo, D. D. R., Monção, N. B. N., Araújo, B. Q., \& Citó, A. M. G. L. (2015). Hypotensive and vasorelaxant effects induced by the ethanolic extract of the Mimosa caesalpiniifolia Benth. (Mimosaceae) inflorescences in normotensive rats. Journal of ethnopharmacology, 164, 120-128.

Sousa, N. J.; Faria, A. B. C.; Corrêa, R. M.; Corrêa, F. A. S. F.; Anjos, R. A. M.; Buturi, E.; Otto, G. M. (2005). Manejo Integrado da Mariposa-do-álamo. In: SEMINÁRIO DE PROTEÇÃO FLORESTAL, 2., Blumenau. Anais... Fupef. 1 CD-ROM.

Vulcano, M. A., \& Pereira, F. S. (1978). The genus Oncideres Serville 1835 (Coleoptera, Lamiidae) in southern Brazil and adjacent countries, a serious pest of orchards and silviculture. Studia Entomologica, 20(1/4), 177-220.

Wylie, F. R., \& Speight, M. R. (2012). Insect pests in tropical forestry. CABI. Zanetti, R.; Santos, A.; Dias, N. S.; Silva, A. S.; Carvalho, G. A. (2005). Manejo integrado de pragas florestais. Lavras: Universidade Federal de Lavras. Editora UFLA.

Zanetti, R.; Santos, A.; Dias, N. S.; Silva, A. S.; Carvalho, G. A. 2005. Manejo integrado de pragas florestais. Lavras: Universidade Federal de Lavras. Editora UFLA.

\section{Porcentagem de contribuição de cada autor no manuscrito}

Márcio Venícius Barbosa Xavier - 25\%

Ana Paula Mota Fonseca - 25\%

Elaine Soares de Almeida - 25\%

Paulo Victor Alves de Oliveira - 25\% 